\title{
Domino effect of pituitary growth hormone tumor complicated by diabetic ketoacidosis and pituitary apoplexy: a case report
}

\author{
JinYu Pan ${ }^{1}$, XiangHong Yang ${ }^{2}$ and Wei Zhu ${ }^{3^{*}}$
}

\begin{abstract}
Background: Patients with growth hormone (GH)-secreting adenoma usually develop glucose intolerance. $\mathrm{GH}$ increases metabolic rate and, when secreted aberrantly, may result in metabolic syndrome. Herein, we examine the associations of pituitary tumor-induced secretion of hormone with insulin resistance and metabolic syndrome, and determine the relation of pituitary tumor apoplexy-induced diabetic ketoacidosis (DKA) and acute pancreatitis.

Case presentation: A 44-year-old male with a history of hypertension presented to the emergency department of our hospital on February 14, 2019 with symptoms of headache, dizziness, and vomiting. Computed tomography of the head revealed pituitary tumor with bleeding. An ultrasound scan of the abdomen revealed fatty liver and acute pancreatitis. Further examination revealed the presence of DKA, hypertriglyceridemia, cortical hypofunction crisis and acute kidney injury. Surgical endoscopic resection of the pituitary tumor resection via the transsphenoidal approach was performed. The patient's postoperative recovery was remarkable.
\end{abstract}

Conclusions: Long-term growth hormone abnormality may trigger insulin resistance, leading to metabolic syndrome and impaired glucose and lipid metabolism. The pituitary adenoma apoplexy may also directly induce DKA, creating a domino effect, which further deteriorate the aberrant metabolism of glucose and lipids.

Keywords: Case report, Acute pancreatitis, Diabetic ketoacidosis, Hypertriglyceridemia, Pituitary growth hormone tumor

\section{Background}

Patients with growth hormone-secreting adenoma usually develop glucose intolerance [1]. Growth hormone $(\mathrm{GH})$ also increases the rate of lipid metabolism, resulting in elevated production of ketone bodies. Coexistence of impaired glucose metabolism, hyperinsulinemia, hypertriglyceridemia (HTG), and hypertension is characteristic of metabolic syndrome (MetS), a cluster of five individual risk factors, including hyperglycemia, hypertriglyceridemia, hypertension, abnormal lipid

\footnotetext{
* Correspondence: david95268@163.com

${ }^{3}$ Department of Emergency Medicine, Zhejiang Provincial People's Hospital (People's Hospital of Hangzhou Medical College), 158 Shangtang Road, 310014 Hangzhou, Zhejiang, People's Republic of China

Full list of author information is available at the end of the article
}

metabolism and abdominal obesity [2]. Although the precise etiology of MetS remains unclear, insulin resistance is a key causative factor, the result of excess circulating fatty acids [2]. HTG may result in acute pancreatitis (AP), which has a global incidence rate of 15-20\% [3]. Together, MetS, hyperglycemia and hyperlipidemia trigger a series of adverse effects in the course of AP $[4,5]$. Here, we report a patient with pituitary tumor apoplexy who complicated diabetic ketoacidosis (DKA) and AP.

\section{Case presentation}

A male patient presented at our hospital for emergency treatment after experiencing headache, dizziness and vomiting for one day. The patient had a four-year

C The Author(s). 2021 Open Access This article is licensed under a Creative Commons Attribution 4.0 International License, which permits use, sharing, adaptation, distribution and reproduction in any medium or format, as long as you give appropriate credit to the original author(s) and the source, provide a link to the Creative Commons licence, and indicate if changes were made. The images or other third party material in this article are included in the article's Creative Commons licence, unless indicated otherwise in a credit line to the material. If material is not included in the article's Creative Commons licence and your intended use is not permitted by statutory regulation or exceeds the permitted use, you will need to obtain permission directly from the copyright holder. To view a copy of this licence, visit http://creativecommons.org/licenses/by/4.0/ The Creative Commons Public Domain Dedication waiver (http://creativecommons.org/publicdomain/zero/1.0/) applies to the data made available in this article, unless otherwise stated in a credit line to the data. 
history of hypertension and had been receiving irbesartan, a blood pressure medication, for control, but his blood pressure was not being monitored regularly. When admitted to the hospital, his consciousness was lucid, body temperature $37.5{ }^{\circ} \mathrm{C}$, pulse 128 beats/minute, 22 breaths/minute, systolic/diastolic blood pressure 82/ $55 \mathrm{mmHg}$; left side pupil $3 \mathrm{~mm}$, right side pupil $4 \mathrm{~mm}$, sensitive to light reflection; no other neurological signs; obvious epigastric tenderness; no other abnormalities in cardiopulmonary abdominal physical examination. Laboratory data showed normal $\mathrm{pO}_{2}$ and $\mathrm{pCO}_{2}$, abnormal blood gas results $(\mathrm{pH} 7.327$, actual base excess -5.1 $\mathrm{mmol} / \mathrm{L}$, standard base excess $-5.0 \mathrm{mmol} / \mathrm{L}$, bicarbonate $19.9 \mathrm{mEq} / \mathrm{L}$ ), Lac $1.6 \mathrm{mmol} / \mathrm{L}$, white blood cell (WBC) count $8.64 \quad\left(10^{\wedge} 9 / \mathrm{L}\right)$, positive $\mathrm{C}$-reactive protein $(31.8 \mathrm{mg} / \mathrm{mL})$, and significantly increased serum levels of triglycerides $(68.07 \mathrm{mmol} / \mathrm{L})$, glucose $(14.89 \mathrm{mmol} / \mathrm{L})$, amylase (279.00 U/L) and lipase (382.00 U/L), slightly elevated serum follicle stimulating hormone $(19.04 \mathrm{IU} / \mathrm{L})$, luteinizing hormone $(5.87 \mathrm{IU} / \mathrm{L})$, prolactin $(0.05 \mathrm{ng} / \mathrm{mL})$, progesterone $<0.10 \mathrm{ng} / \mathrm{mL}$, testosterone $(1.08 \mathrm{ng} / \mathrm{mL})$, cortisol $(16.70 \mathrm{ug} / \mathrm{dL})$, corticotropin $(10.00 \mathrm{pg} / \mathrm{mL})$, calcium $(2.18 \mathrm{mmol} / \mathrm{L})$, serum creatinine $(54.40 \mathrm{mmol} / \mathrm{L})$, and growth hormone $(28.70 \mathrm{ng} / \mathrm{mL})$. We did not measure the level of IGF-1, for it is positively associated with the level of $\mathrm{GH}$ [6]. The glycated hemoglobin HbA1 $(17.6 \%)$ and HbA1c (15.1\%) were both remarkably higher than the upper limit of normal range. Urine ketones $(++++)$, coagulation factors and hepatic enzymes were within normal limits. The insulin level and $C$ peptide level were not measured. Laboratory values are described in detail in Table 1.

Relevant imaging examinations on admission revealed that computed tomography $(\mathrm{CT})$ and magnetic resonance imaging (MRI) of the head indicated pituitary tumor with hemorrhage (Fig. 1) and acute necrotizing pancreatitis with peripancreatic effusion (Fig. 2). According to admitted results of above examinations and abdominal ultrasound, patients were diagnosed as severe acute pancreatitis, diabetic ketoacidosis, emergency pituitary tumor with hemorrhage, hypovolemic shock, fatty liver and hypertension. Diabetic ketoacidosis was diagnosed due to the abnormal results of blood gas test, which suggested the patient may have metabolic acidosis even though the $\mathrm{pH}$ value was not so much low. On the other hand, hypertension was diagnosed 4 years ago, which may indicate the time when GH excess started.

The patient's symptoms of headache, vomiting, abdominal distention, shortness of breath and oliguria disappeared at 3 day of emergency intensive care unit (EICU). The patient was ill on February 14, 2019. He underwent transsphenoidal endoscopic pituitary tumor resection 11 days after being transferred from EICU. His
Table 1 Laboratory findings during hospitalization

\begin{tabular}{lll}
\hline Laboratory test & Results & Normal range \\
\hline Blood biochemistry & & \\
WBC & $8.64^{*} 10 \wedge 9 / \mathrm{L}$ & $4.50-11.00^{*} 10 \wedge 9 / \mathrm{L}$ \\
Lactate & $1.60 \mathrm{mmol} / \mathrm{L}$ & $0.50-1.00 \mathrm{mmol} / \mathrm{L}$ \\
Serum creatinine & $54.40 \mathrm{mmol} / \mathrm{L}$ & $58.00-110.00 \mathrm{mmol} / \mathrm{L}$ \\
Glucose & $14.89 \mathrm{mmol} / \mathrm{L}$ & $4.20-6.100 \mathrm{mmol} / \mathrm{L}$ \\
C-reactive protein & $31.80 \mathrm{mg} / \mathrm{mL}$ & $0.00-10.00 \mathrm{mg} / \mathrm{m} \mathrm{L}$ \\
Triglycerides & $68.07 \mathrm{mmol} / \mathrm{L}$ & $0.34-1.70 \mathrm{mmol} / \mathrm{L}$ \\
Total cholesterol & $21.64 \mathrm{mmol} / \mathrm{L}$ & $3.11-5.96 \mathrm{mmol} / \mathrm{L}$ \\
Pancreatic amylase & $348.00 \mathrm{U} / \mathrm{L}$ & $0.00-53.00 \mathrm{U} / \mathrm{L}$ \\
Lipase & $382.00 \mathrm{U} / \mathrm{L}$ & $16.00-63.00 \mathrm{U} / \mathrm{L}$ \\
Amylase & $279.00 \mathrm{U} / \mathrm{L}$ & $30.00-110.00 \mathrm{U} / \mathrm{L}$ \\
Calcium & $2.18 \mathrm{mmol} / \mathrm{L}$ & $2.10-2.80 \mathrm{mmol} / \mathrm{L}$ \\
Bicarbonate & $19.90 \mathrm{mEq} / \mathrm{L}$ & $21.00-29.00 \mathrm{mEq} / \mathrm{L}$ \\
HbA1 & $17.60 \%$ & $6.30-9.00 \%$ \\
HbA1c & $15.10 \%$ & $3.60-6.00 \%$ \\
Hormonal data & & \\
Cortisol & & \\
Corticotropin & $16.70 \mathrm{ug} / \mathrm{L}$ & $67.00-226.00 \mathrm{ug} / \mathrm{L}$ \\
Follicle stimulating hormone & $19.04 \mathrm{IU} / \mathrm{L}$ & $0.90-12.00 \mathrm{IU} / \mathrm{L}$ \\
Luteinizing hormone & $5.87 \mathrm{IU} / \mathrm{L}$ & $0.60-12.10 \mathrm{IU} / \mathrm{L}$ \\
Estradiol & $<10.00 \mathrm{pg} / \mathrm{mL}$ & $11.00-44.00 \mathrm{pg} / \mathrm{mL}$ \\
Prolactin & $0.05 \mathrm{ng} / \mathrm{mL}$ & $3.50-19.40 \mathrm{ng} / \mathrm{mL}$ \\
Testosterone & $1.08 \mathrm{ng} / \mathrm{mL}$ & $1.60-8.10 \mathrm{ng} / \mathrm{mL}$ \\
Progesterone & $<0.10 \mathrm{ng} / \mathrm{mL}$ & $0.13-0.97 \mathrm{ng} / \mathrm{mL}$ \\
Growth hormone & $28.70 \mathrm{ng} / \mathrm{mL}$ & $0.06-5.00 \mathrm{ng} / \mathrm{mL}$ \\
Urinary biochemistry & & \\
Urine amylase & & $32.00-641.00 \mathrm{U} / \mathrm{L}$ \\
Urine ketone bodies & & - \\
\hline
\end{tabular}

postoperative recovery was good. Metabolic parameters have greatly improved at postoperative 1-month and 5month (Supplementary Table 1). DKA was not diagnosed after surgery. Blood glucose levels as represented by the level of HbA1 and HbA1c, and the blood pressure returned to normal. The preoperative and postoperative BMI was 31.1 and 25.9, respectively. Routine histopathological examination and diagnostic evaluation suggested that "pituitary tumor in sellar region" was consistent with pituitary adenoma with extensive hemorrhagic infarction and secondary inflammatory fiber hyperplasia. Immunohistochemistry results were positive for $\mathrm{GH}(+)$, syn (+), CD56 (+), CGA (+), ER (focus + ), cam $5.2(+)$ and CK (Pan), and were negative for ACTH (-), FSH (-), TSH (-), LH (-), PRL (-), PR (-), Ki67 (1-2\%), and p53 $(-)$. However, despite the well recovery, hypocortisol state and central hypothyroidism were observed after surgery. We treated the patient with cortisol $20 \mathrm{mg}$ 


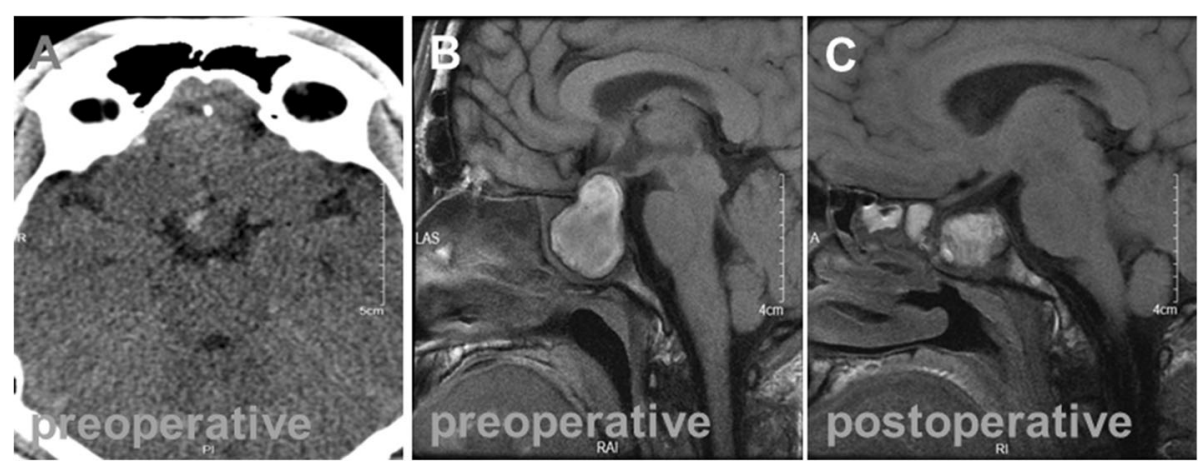

Fig. 1 The brain images of the patient were evaluated by CT and MRI. a Preoperative computed tomography revealed pituitary hemorrhage (white arrow). b Preoperative contrast-enhanced T1-weighted magnetic resonance images exhibited pituitary tumor with hemorrhage, lobulated mass measuring $2.6 \times 2.7 \times 3.2 \mathrm{~cm}$ at the sella region with a prominent suprasellar component and vascular encasement. c Postoperative MRI images showed no residual tumor

twice a day (morning and evening) and Euthyrox $25 \mathrm{ug}$ once a day orally.

During treatment, active volume resuscitation and antacid-medicated stomach protection were noted. Further examination during the course of treatment revealed diabetic ketoacidosis, hyperlipidemia, hypocortical crisis (pituitary apoplexy, shock, ahyponatremia, low random total cortisol, and increase of production and secretion of $\mathrm{ACTH}$ ), and acute kidney injury (based on KDIGO criteria and the condition that the serum creatinine level has raised from $54.4 \mathrm{umol} / \mathrm{L}$ on admission to $112 \mathrm{umol} / \mathrm{L} 16 \mathrm{~h}$ before transferred to EICU), as well as shortness of breath and decreased blood oxygen saturation. A large amount of hydrops was found in the abdominal cavity and pelvic cavity, which were treated once by plasma adsorption, and hydrocortisone $200 \mathrm{mg} /$ $\mathrm{D}$ micropump maintenance treatment, insulin hypoglycemia, abdominal puncture drainage and other symptomatic support treatment. No obvious abnormalities in the patient's diagnostic indicators were found during follow-up in the outpatient clinic for nearly half a year. The patient was contacted by the hospital via phone follow-up to the present. Long-term chronic use of thyroxine tablets and prednisone continued until the present, and the patient had normal blood glucose, slightly higher triglyceride levels $(2.88 \mathrm{mmol} / \mathrm{L})$, but no recurrence of pancreatitis.

\section{Discussion}

The triad of DKA, HTG, and AP in a single patient has only rarely been reported in the literature [7]. In DKA, severe insulin deficiency can lead to disorders of glucose and lipid metabolism, which further leads to development of HTG and ultimately the resulting AP. When AP combines with DKA, it not only delays the diagnosis of AP due to the lack of specific symptoms and biomarkers, but also increases the consumption of hyperglycemia and vascular content. However, concurrent DKA has not been found to affect morbidity and mortality in patients with HTG-induced pancreatitis [8].

Growth hormone pituitary tumor apoplexy with DKA is also a relatively rare complication in adults [9]. Insulin insufficiency due to excessive growth hormone may be associated insulin resistance, glucose intolerance, and type 2 diabetes [10]. Impaired glucose and lipid homeostasis is the main feature of MetS [11]. Insulin resistance is considered to be a key factor in the development of MetS, and HTG is frequently observed in diabetic
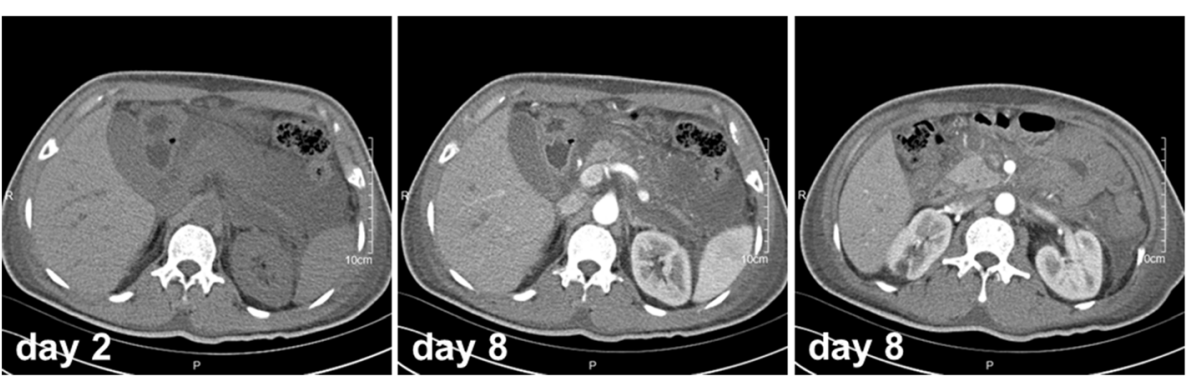

Fig. 2 Abdominal computed tomography exhibited acute necrotizing pancreatitis with peripancreatic effusion and local intestinal wall thickening on day 2 and day 8 of admission 
patients [12]. Patients with MetS, including diabetes, often manifest a typical lipid profile referred to as "diabetic dyslipidemia" [13].

Acute stress events, such as cerebrovascular accidents, infections and trauma, may add to the already disordered glucose and lipid metabolism in patients with MetS, directly inducing DKA [14]. During the course of DKA, insulin insufficiency activates the decomposition and release of fats from adipose tissue, leading to acceleration of very low-density lipoprotein (VLDL) synthesis in the liver, which is owed directly to elevated free fatty acid levels. In addition, the decreased lipoprotein lipase activity in peripheral tissues reduces removal of plasma VLDL, resulting in HTG [15], and moderate HTG is common during the onset of DKA [16], which induces direct toxicity in the pancreatic acinar cells and pancreatic capillaries. Meanwhile, HTG-induced pancreatitis may cause acute $\beta$-cell dysfunction, resulting in transient insulin deficiency and exacerbating ketoacidosis.

The triad of DKA, HTG, and AP may be associated with the level of HTG [17]. Severe HTG-related AP is an under-recognized disease [18], and hyperlipidemia appears to be the primary cause and phenomenon for AP attacks [19]. Studies that have examined the effect of previous diabetes on AP outcomes report that the risk of AP in diabetic patients is about $30 \%$ higher than in those without diabetes [20]. DM and MetS, especially MetS including obesity and hyperlipidemia, are noted to have adverse effects on the course of AP, especially the impact on multiple organ systems, including the pancreas; in particular, severe HTG can lead to increased morbidity and mortality [5].

DKA is a rare manifestation of pituitary adenoma apoplexy. In our patient, the pituitary adenoma apoplexy seemed to directly induce DKA, creating a domino effect, which increases the already disordered metabolism of glucose and lipids in patients with MetS. The relative lack of insulin is accompanied by increased ketogenic activity in adipose tissue and glucagon in the liver. Moreover, the lack of insulin activates lipolysis and reduces VLDL in plasma during the course of DKA, and subsequent clearance then leads to HTG [15]. Hyperlipidemia is likely to be the main cause and phenomenon of AP, with risk of AP increased by high concentration of triglycerides [21]. Therefore, associations appear to exist between ketoacidosis, hyperlipidemia, and AP. Diabetes or impaired glucose tolerance are independent risk factors for AP secondary to HTG [22]. Patients with AP have higher risk of comorbid DKA and a history of diabetes, and serum triglyceride levels are significantly higher in these patients [23]. The long-term glyco- and lipotoxicities identified in our patient resulted in DKA, which is known to result from severe, but partially reversible, $\beta$-cell dysfunction. Classified as ketosis- ketodiabetes (KPD) syndrome, growth hormone control serves to maintain blood glucose at somewhat normal levels [24]. After the resection of the pituitary tumor, our patient was advised to stop insulin treatment, which was not only effective in regulating blood glucose levels, but also lowered triglyceride levels significantly (68.07 vs. $2.88 \mathrm{mmol} / \mathrm{L}$ ).

DKA, HTG and AP can be seen with pituitary tumor in adult. Early recognition of these symptoms has important implications in the management of the patient as resection of the pituitary tumor, recovery duration, and prognosis can be altered. In patients presenting with ketoacidosis and elevated lipase levels, the treating physicians may perform serum amylase tests and early abdominal imaging in order to reach an early diagnosis of AP. In the presence of MetS and abnormally increased growth hormone levels, acute stress-induced metabolic disorders may be highly suspected. In such patients, thorough relevant examinations must be conducted, pituitary tumors and endocrine factors must be excluded, and the etiology must be clarified in order to manage diabetes and triglyceride levels effectively after tumor resection.

\section{Abbreviations}

AP: Acute pancreatitis; CT: Computed tomography; DKA: Diabetic ketoacidosis; GH: Growth hormone; HTG: Hypertriglyceridemia; KPD: Ketosisketodiabetes; MetS: Metabolic syndrome; MRI: Magnetic resonance imaging; VLDL: Very low-density lipoprotein; WBC: White blood cell

\section{Supplementary Information}

The online version contains supplementary material available at https://doi. org/10.1186/s12902-021-00768-9.

\section{Additional file 1:}

Acknowledgements

None.

Authors' contributions

XHY had made substantial contributions to the conception, WZ contributed to study design; JYP collected the data; WZ analyzed the data; JYP prepared the manuscript, WZ did critical revision of the manuscript; and all authors read and approved the final version for submission.

\section{Funding}

Grants from the Health Bureau of Zhejiang province(2019KY314), the funding body plays no role in the design of the study and collection, analysis, and interpretation of data and in writing the manuscript.

\section{Availability of data and materials}

The data used to support the findings of this study are included within the article.

\section{Declarations}

Ethics approval and consent to participate Not applicable. 


\section{Consent for publication}

Written informed consent was obtained for the publication of this case report. Moreover, the patient gave written consent for his personal or clinical details along with any identifying images to be published in this study.

\section{Competing interests}

The author reports no conflicts of interest in this work.

\section{Author details}

'Graduate Department, BengBu Medical College, 233030 Bengbu, Anhui, China. ${ }^{2}$ Department of Intensive Care Uint, Zhejiang Provincial People's Hospital (People's Hospital of Hangzhou Medical College), 310014 Hangzhou, Zhejiang, China. ${ }^{3}$ Department of Emergency Medicine, Zhejiang Provincial People's Hospital (People's Hospital of Hangzhou Medical College), 158 Shangtang Road, 310014 Hangzhou, Zhejiang, People's Republic of China.

Received: 10 February 2021 Accepted: 16 May 2021

Published online: 26 May 2021

\section{References}

1. Mori K, Iwasaki Y, Kawasaki-Ogita Y, Honjo S, Hamamoto Y, Tatsuoka H, et al. Improvement of insulin resistance following transsphenoidal surgery in patients with acromegaly: correlation with serum IGF-I levels. J Endocrinol Invest. 2013;36(10):853-9.

2. Wang HH, Lee DK, Liu M, Portincasa P, Wang DQ. Novel Insights into the Pathogenesis and Management of the Metabolic Syndrome. Pediatr Gastroenterol Hepatol Nutr. 2020;23(3):189-230.

3. Scherer J, Singh VP, Pitchumoni CS, Yadav D. Issues in hypertriglyceridemic pancreatitis: an update. J Clin Gastroenterol. 2014;48(3):195-203.

4. Mikolasevic I, Milic S, Orlic L, Poropat G, Jakopcic I, Franjic N, et al. Metabolic syndrome and acute pancreatitis. Eur J Intern Med. 2016;32:79-83.

5. Shemesh E, Zafrir B. Hypertriglyceridemia-Related Pancreatitis In Patients With Type 2 Diabetes: Links And Risks. Diabetes Metab Syndr Obes. 2019;12: 2041-52.

6. Tanimoto K, Hizuka N, Fukuda I, Takano K, Hanafusa T. The influence of age on the GH-IGF1 axis in patients with acromegaly. Eur J Endocrinol. 2008; 159(4):375-9.

7. Kumar P, Sakwariya A, Sultania AR, Dabas R. Hypertriglyceridemia-induced acute pancreatitis with diabetic ketoacidosis: A rare presentation of type 1 diabetes mellitus. J Lab Physicians. 2017;9(4):329-31.

8. Wang Y, Attar BM, Hinami K, Jaiswal P, Yap JE, Jaiswal R, et al. Concurrent Diabetic Ketoacidosis in Hypertriglyceridemia-Induced Pancreatitis: How Does It Affect the Clinical Course and Severity Scores? Pancreas. 2017;46(10): 1336-40.

9. Ocampo P, Duarte JM, Barcia R, Arevalo C. [Association between diabetic ketoacidosis and acromegaly]. Medicina. 2018;78(2):131-3.

10. Reddy R, Hope S, Wass J, Acromegaly. BMJ. 2010:341:c4189.

11. Alberti KG, Zimmet P, Shaw J, Group IDFETFC. The metabolic syndrome-a new worldwide definition. Lancet. 2005;366(9491):1059-62.

12. Hirano T. Pathophysiology of Diabetic Dyslipidemia. J Atheroscler Thromb. 2018;25(9):771-82

13. Tehrani DM, Zhao Y, Blaha MJ, Mora S, Mackey RH, Michos ED, et al. Discordance of Low-Density Lipoprotein and High-Density Lipoprotein Cholesterol Particle Versus Cholesterol Concentration for the Prediction of Cardiovascular Disease in Patients With Metabolic Syndrome and Diabetes Mellitus (from the Multi-Ethnic Study of Atherosclerosis [MESA]). Am J Cardiol. 2016;117(12):1921-7.

14. Dhatariya KK, Glaser NS, Codner E, Umpierrez GE. Diabetic ketoacidosis. Nat Rev Dis Primers. 2020;6(1):40.

15. Fulop M, Eder H. Severe hypertriglyceridemia in diabetic ketosis. Am J Med Sci. 1990;300(6):361-5.

16. Fulop M, Eder HA. Plasma triglycerides and cholesterol in diabetic ketosis. Arch Intern Med. 1989:149(9):1997-2002.

17. Timilsina S, Timilsina S, Mandal A, Paudel R, Gayam V. Triad of Diabetic Ketoacidosis, Hypertriglyceridemia, and Acute Pancreatitis: Severity of Acute Pancreatitis May Correlate with the Level of Hypertriglyceridemia. Cureus. 2019:11(6):e4930.

18. Zeng Y, Zhang W, Lu Y, Huang C, Wang X. Impact of hypertriglyceridemia on the outcome of acute biliary pancreatitis. Am J Med Sci. 2014;348(5): 399-402.
19. Charlesworth A, Steger A, Crook MA. Acute pancreatitis associated with severe hypertriglyceridaemia; A retrospective cohort study. Int J Surg. 2015: 23(Pt A):23-7.

20. Shen HN, Lu CL, Li CY. Effect of diabetes on severity and hospital mortality in patients with acute pancreatitis: a national population-based study. Diabetes Care. 2012;35(5):1061-6.

21. Adiamah A, Psaltis E, Crook M, Lobo DN. A systematic review of the epidemiology, pathophysiology and current management of hyperlipidaemic pancreatitis. Clin Nutr. 2018;37(6 Pt A):1810-22.

22. Li Q, Hou C, Peng Y, Zhu X, Shi C, Zhang K, et al. Diabetes and Younger Age Are Vital and Independent Risk Factors for Acute Pancreatitis in Patients with Severe Hypertriglyceridemia. Biomed Res Int. 2019;2019: 2620750.

23. Yuan S, Liao J, Cai R, Xiong Y, Zhan H, Zheng Z. Acute pancreatitis concomitant with diabetic ketoacidosis: a cohort from South China. J Int Med Res. 2020;48(3):300060520912128.

24. Balasubramanyam A, Nalini R, Hampe CS, Maldonado M. Syndromes of ketosis-prone diabetes mellitus. Endocr Rev. 2008;29(3):292-302.

\section{Publisher's Note}

Springer Nature remains neutral with regard to jurisdictional claims in published maps and institutional affiliations.
Ready to submit your research? Choose BMC and benefit from:

- fast, convenient online submission

- thorough peer review by experienced researchers in your field

- rapid publication on acceptance

- support for research data, including large and complex data types

- gold Open Access which fosters wider collaboration and increased citations

- maximum visibility for your research: over $100 \mathrm{M}$ website views per year

At BMC, research is always in progress.

Learn more biomedcentral.com/submissions 